\title{
Enhanced Oil Recovery
}

\author{
MD. KHAJA MUZZAFARUDDIN* \\ M.Tech, (Petroleum Exploration \& Production)
}

\author{
*Corresponding Author: MD. KHAJA MUZZAFARUDDIN, M.Tech, (Petroleum Exploration \& \\ Production)
}

\begin{abstract}
Primary and secondary methods of oil recovery are mainly used to recover the lighter, less viscous crude oil. Thermal enhanced oil recovery is popular method of extracting the harder-to-obtain heavy crude oil. The primary concept of thermal enhanced oil recovery is to lower the viscosity of the heavy crude oil with heat. Lowering the viscosity gives the crude oil mobility to move towards the production well. The main methods of thermal enhanced oil recovery include cyclic steam stimulation (CSS), steam-assisted gravity drainage (SAGD), and in-situ combustion. Environmentally friendly methods of thermal enhanced oil recovery include solar power. The other methods of enhanced oil recovery are gas and chemical injection.
\end{abstract}

\section{INTRODUCTION}

Most of the easier-to-produce oil has been recovered by conventional methods, also known as primary and secondary recovery techniques. Heavy crude oil, as opposed to light crude oil, has a higher density, viscosity, and specific gravity and does not flow easily under normal reservoir conditions. Enhanced oil recovery methods have been developed in order to maximize oil production and recovery by lowering viscosity and increasing the sweep efficiency. Thermal enhanced oil recovery is used to recover heavy crude oil in the United States, Canada, and Venezuela using heat and combustion.

According to the U.S. Department of Energy, oil is extracted in three steps: primary recovery, secondary recovery, and enhanced oil recovery. Primary recovery involves natural mechanisms, such as the pressure in the reservoir or gravity, to push oil to a wellbore where it is pumped to the surface, resulting in a recovery of about $10 \%$ of the total oil in the formation. Secondary recovery is the injection of fluids, such as water or gas, to displace the oil, recovering 20 to 40 percent of the original oil. Primary and secondary methods are used to recover light crude oil, which is less dense and viscous than heavy crude oil and therefore easier to recover. Enhanced oil recovery (EOR), the final phase, combines primary and secondary recovery techniques to create a highly effective method of oil production, extracting 30 to $60 \%$ of the oil in a field.

\section{Thermal ENhanced Oil Recovery}

Thermal enhanced oil recovery, or thermal EOR, uses heat as a mechanism to drive oil in a field to a wellbore for production. The concept of oil recovery typically involves the creation of a pressure gradient within the formation. Pressure drives the oil to the production wells to be pumped to the surface. In the case of thermal EOR, increasing the temperature of the formation using a variety of steam injection methods lowers the viscosity of heavy crude oil, allowing the oil to flow easily towards the production well. Thermal methods account for $40 \%$ of EOR in the United States and are predominantly in California (U.S. Dept. of Energy). The main methods of thermal EOR are cyclic steam stimulation (CSS), steam flooding, and in situ combustion.

\subsection{Cyclic Steam Stimulation (CSS)}

Cyclic steam stimulation (CSS) is commonly used in Canada to recover bitumen from oil sands. Bitumen, more popularly known as asphalt, is a highly viscous liquid or semi solid form of petroleum that is found deep beneath the Earth's surface. Its location makes it difficult to mine. The first phase of CSS is steam injection. Steam is injected through a wellbore over the course of weeks to increase 
the temperature of the bitumen. As the temperature increases, it becomes easier for the bitumen to move. The second phase is simply allowing the heat to dissipate in the formation. The third phase reverses the flow of the wellbore to pump oil through it to the surface, which may take several months (Canada Natural). Cyclic steam stimulation is repeated until injecting steam costs more than producing oil. The recovery factor is typically around 20 to 25 percent (U.S. Dept. of Energy). Cyclic steam stimulation is often done at high pressures, resulting in a technique called High Pressure Cyclic Steam Stimulation (HPCSS). Hou and colleagues explored cyclic steam stimulation optimization by horizontal wells and found that in field applications, using one well for both injection and oil production is not ideal, which leads to the next type of thermal EOR.

\subsection{Steam Assisted Gravity Drainage (SAGD)}

Steam flooding both increases the temperature of the formation and creates a pressure gradient in order to enhance oil recovery. By creating a pressure gradient, the steam displaces the oil, similar to the process of secondary recovery, in which water or gas is used. In the 1970s, Dr. Roger Butler, an engineer at Imperial Oil in Alberta, Canada, invented steam-assisted gravity drainage (SAGD), a popular form of steam flooding. Horizontal wells are drilled into an oil reservoir. High-pressure steam is continuously injected into the upper well, heating the oil around it. The increase in temperature lowers the oil's viscosity, causing it to drain to the lower wellbore, where it is pumped to the surface. According to an article released by Alberta Oil Magazine, typical SAGD projects cost as much as $\$ 1.5$ billion to produce 30,000 barrels per day.

Research and mathematical modeling has been conducted to evaluate the efficiency of various well configurations. Butler, of Imperial Oil, and his colleague Stephens reported that for efficient oil production in parallel horizontal wells, continuous steam injection and oil drainage is necessary. In 1986, Joshi explored the theory of a vertical injector above a horizontal well and found that vertical injectors had higher recovery outcomes than horizontal injectors above a horizontal well. Joshi also found that vertical fractures in the formation that are perpendicular to the horizontal well increase the recovery rate. The effect of the distance between the horizontal injector and well on oil production has been studied as well. By performing experimental modeling of SAGD, Sasaki et al. found that the rate of production increased as the spacing between wells increased.

\subsection{In-Situ Combustion}

In-situ combustion involves the injection of an oxygen-containing gas into a reservoir and igniting it, creating a combustion zone that drives oil toward a production well. In-situ combustion is also known as fire flooding because of the movement of the combustion front inside the reservoir. This form of thermal EOR can be done in two ways: forward or reverse. Forward combustion is when the combustion front moves in the same direction as the oxidizing gas. In reverse combustion, the combustion front travels in the opposite of the flow of the oxidizing gas. Forward combustion is mainly used in the oil industry and has a recovery factor anywhere from 39 to 56 percent. Reverse combustion has been studied and tested in the field but is not commonly used because of problems such as unreacted oxygen causing corrosion and requiring more oxygen in order to propagate the combustion zone (Naccache et al.)

\subsection{Technical Limitations}

While the effectiveness of thermal enhanced oil recovery is apparent, there are drawbacks and limitations. In both CSS and SAGD, by increasing the temperature of the steam, the viscosity of the oil is lowered. However, there is a temperature limit the steam cannot exceed given the metallurgical considerations of the materials used in oil production, specifically the wells must be able to transport steam and oil without melting. The steam used in thermal enhanced oil recovery is also power hungry. Water requires a large sum of money to treat and large amount of energy to vaporize. Steam production consumes enormous amounts of water and natural gas and is therefore costly. There is also the issue of $\mathrm{CO}_{2}$ emissions due to the steam generation.

According to Canada Natural, SAGD has a typical recovery factor of greater than 50\%, much higher than CSS. However, according to E.L. Lui, the Vice President of Oil Sands Development and Research at Imperial Oil, CSS is more effective than SAGD because of its ability to be used in a wider range of reservoirs. The high-pressure steam raises the formation above which then, due to gravity, pushes the oil back towards the wellbore. It is clear that CSS and SAGD are very similar. 
They are similar because of the continuous steam injection. However, they differ in the method of oil extraction. For CSS, the steam is allowed to dissipate in the formation and only after is the oil drained through the same well as the steam injection. For SAGD, the oil is drained continuously through a separate well. In the research Hou et al. conducted for the optimization of CSS using horizontal wells, they found that more wells would increase efficiency.

In in-situ combustion, the primary problems are the highly uncontrollable combustion front, corrosion causing unreacted oxygen and fluid blocking. Fluid blocking is when the flow of the hot lower viscosity hydrocarbons at the top of the injection well is hindered by the slower rate of flow of the higher viscosity hydrocarbons at the production part of the well. This happens because the combustion front occurs at the top of the well, heating the lower viscosity hydrocarbons, which are stopped by the higher viscosity hydrocarbons beneath. This makes the process less efficient. However, in-situ combustion has advantages over CSS and SAGD. It avoids the cost of heating water because it only needs compressors for the air. It also does not emit as much $\mathrm{CO}_{2}$ into the atmosphere as compared to both CSS and SAGD (Naccache et al.)

\subsection{Current Outlook}

While thermal EOR is declining in the United States, current improvement on thermal enhanced oil recovery technology includes a more efficient and environmentally friendly outlook in other regions. Rather than burning natural gas in order to heat steam for injection, solar enhanced oil recovery implements solar panel technology to harness the sun's energy for heating water into steam. Glass Point Solar is the first to create a solar steam generating system for thermal EOR. Their greenhouses enclose mirrors in order to protect the equipment from debris and humidity. The lightweight mirrors are used to concentrate solar energy to heat water. With solar thermal EOR, there is a high capital cost compared to natural gas; installing such an operation is expensive. Natural gas, however, has to be constantly supplied as well as the water. Solar thermal EOR does not consume any fuel, reducing the cost of operation, and does not produce greenhouse gases. In the long run, solar EOR does have the advantage compared to previous methods (Chaar et al.)

\section{OTHER METHODS OF ENHANCED OIL RECOVERY}

Other enhanced oil recovery techniques include miscible gas injection and chemical injection. These methods are typically used to recover lighter oils. Miscible gas injection works by removing the surface tension between the oil and the gas displacing it. Carbon dioxide and nitrogen are the most commonly used gases. However, both have their own set of problems. Carbon dioxide is good choice because of its miscibility with oil at low pressures and temperatures. Carbon dioxide injection requires a source, either a natural source or from separation from a hydrocarbon gas, and therefore many oilfields are near natural sources of carbon dioxide. However, extreme care must be taken when designing oil recovery systems because of possible corrosion. Nitrogen, on the other hand, is miscible with oil at a relatively high pressure. It also requires quite a bit of work to separate it from air. Therefore, the use of carbon dioxide is more common. In the United States, gas injection accounts for almost 60 percent of EOR (U.S. Dept. of Energy).

Chemical injection can be done in many ways. The use of surfactants and alkalis reduces surface tension between the crude oil and the injected water from the secondary phase. Polymer flooding changes the water viscosity to match that of oil. The surfactants and polymers are very expensive and often their cost outweighs the cost of oil. It has been found that polymer flooding for an extended period of time causes scaling, which is when there is large amount of deposits on the metal surfaces of the wells. Therefore only $1 \%$ of United States EOR is by chemical injection (U.S. Dept. of Energy).

\section{CONCLUSION}

Thermal enhanced oil recovery is a type of oil production mainly used for the extraction of heavy crude oil. Much of the lighter crude oil has been recovered by primary and secondary methods, which depends on simpler mechanisms such as gravity and water injection. Other methods of enhanced oil recovery exist: gas injection and chemical injection. Every type of oil recovery has its advantages and disadvantages. The United States primarily uses $\mathrm{CO}_{2}$ gas injection while Canada uses both CSS and SAGD. The current outlook in thermal enhanced oil recovery implements solar power into heating water to generate steam. 


\section{REFERENCES}

[1] Butler, R.m., and D.j. Stephens. "The Gravity Drainage of Steam-heated Heavy Oil to Parallel Horizontal Wells." Journal of Canadian Petroleum Technology 20.02 (1981): n. pag. Web.

[2] Chaar, Marwan, Milton Venetos, Justin Dargin, and Daniel Palmer. "Economics Of Steam Generation For Thermal Enhanced Oil Recovery." Oil and Gas Facilities 4.06 (2015): 42-50. Web.

[3] "Enhanced Oil Recovery." United States Department of Energy.N.p., n.d. Web. 07 May 2016. <http://energy.gov/fe/science-innovation/oil-gas-research/enhanced-oil-recovery>.

[4] Hou, Jian, Kang Zhou, Hui Zhao, XiaodongKang, Shutao Wang, and Xiansong Zhang. "Hybrid Optimization Technique for Cyclic Steam Stimulation by Horizontal Wells in Heavy Oil Reservoir." Computers \& Chemical Engineering 84 (2016): 363-70. Web.

[5] Joshi, S.d. "A Laboratory Study of Thermal Oil Recovery Using Horizontal Wells." Proceedings of SPE Enhanced Oil Recovery Symposium (1986): n. pag. Web.

[6] Naccache, Paul, and Aubrey O'Callaghan. Understanding in Situ Combustion (2007): n. pag. Schlumberger. Web. <http://www.slb.com/ /media/Files/industry_challenges/ heavy_oil/ other/feature_ articles/ho in_situ_combustion.pdf $>$.

[7] Snyder, Jesse. "The Search for the Lowest-cost Barrel and the Future of the Alberta Oil Sands - Alberta Oil Magazine." Alberta Oil Magazine. Alberta Oil Magazine, 07 Sept. 2015. Web. 12 May 2016. <http://www.albertaoilmagazine.com/2015/09/the-future-of-the-alberta-oil sands/>.

[8] "Thermal in Situ Oil Sands." Canadian Natural. Canada Natural Resources, n.d. Web. 10 May 2016. <http://www.cnrl.com/operations/north-america/north-american crude-oil-and-ngls/thermal-insitu-oilsands />

Citation: MD. KHAJA MUZZAFARUDDIN, (2019). "Enhanced Oil Recovery", International Journal of Petroleum and Petrochemical Engineering (IJPPE), 5(4), pp.10-13, DOI: http://dx.doi.org/10.20431/24547980.0504002

Copyright: () 2019 Authors. This is an open-access article distributed under the terms of the Creative Commons Attribution License, which permits unrestricted use, distribution, and reproduction in any medium, provided the original author and source are credited 